\title{
ESTRATÉGIAS ARGUMENTATIVAS NO FACEBOOK DO MOVIMENTO \#YOSOY132 PÓS-ELEIÇÃo PRESIDENCIAL MEXICANA DE 2012
}

\author{
GABRIEL BOZZA \\ Universidade Federal do Paraná \\ Curitiba, Paraná, Brasil \\ E-mail: gabrielbozz@gmail.com. \\ LUCIANA PANKE \\ Universidade Federal do Paraná \\ Curitiba, Paraná, Brasil \\ E-mail: lupanke@gmail.com
}


ESTRATÉGIAS ARGUMENTATIVAS NO FACEBOOK DO MOVIMENTO \#YOSOY132 PÓS-ELEIÇÃO PRESIDENCIAL MEXICANA DE 2012

Resumo: As eleições presidenciais mexicanas, em 2012, tiverem a participação do movimento \#YoSoy132. Este estudo investiga se o grupo continuou com suas ações online depois das eleições. Analisamos 142 postagens do Facebook, de julho a dezembro de 2012, sob o viés da Teoria da Argumentação (PERELMAN, OLBRECHTS-TYTECA, 1996). Verificamos que o grupo está ativo, manifestando-se sobre as decisões do governo.

Palavras-chave: Comunicação Política; \#Yosoy132; México; Facebook.

ESTRATEGIAS ARGUMENTATIVAS EN FACEBOOK DE MOVIMIENTO \#YOSOY132 DESPUES DE ELECCIÓN PRESIDENCIAL MEXICANA DE 2012

Resumen: Las elecciones presidenciales mexicanas en 2012, cuenta con la participación del movimiento \#YoSoy132. Este estudio investiga si el grupo continuó con sus acciones online depois las elecciones de. Se analizaron 142 posts de Facebook, de julio a diciembre de 2012, bajo la Teoría de la Argumentación (PERELMAN, OLBRECHTS-TYTECA, 1996). Ha comprobado que el grupo está activo, apareciendo en las decisiones del gobierno

Palabras clave: Comunicación Política; \#YoSoy132; México; Facebook.

ARGUMENTATIVE STRATEGIES IN FACEBOOK OF MOVEMENT \#YOSOY132 AFTER MEXICAN PRESIDENTIAL ELECTION 2012

Abstract: The mexican presidential elections in 2012 has the participation of the movement \#YoSoy132. This study investigates whether the group continued with their actions online after the elections. We analyzed 142 posts from Facebook, between July 3 and December 3, 2012, under the Theory of Argumentation (PERELMAN, OLBRECHTS-TYTECA, 1996). Verified that the group is active, showing up on government decisions.

Keywords: Political communication; \#YoSoy132; México; Facebook. 


\section{INTRODUÇÃO}

Esse artigo tem como objetivo principal verificar se houve a continuação das causas defendidas pelo movimento \#YoSoy132 depois da eleição presidencial mexicana de 2012. Na primeira parte deste artigo apresentamos o surgimento do \#YoSoy132 e o contexto eleitoral que serviu de suporte para as estratégias coordenadas pelas redes sociais digitais por ativistas políticos. Entendemos que, para isso, é importante compreender como as redes sociais dão suporte para ações e estratégias coordenadas por ativistas políticos.

Na segunda etapa apresentamos a Teoria da Argumentação elaborada pelos belgas Chaïm Perelman e por Lucie Olbrechts-Tyteca (1996). Aplicamos a metodologia proposta pelos autores numa base empírica composta por 142 postagens realizadas no perfil oficial do Facebook do movimento \#YoSoy132, no período de 03 de julho de 2012 a 03 de dezembro de 2012, correspondente ao período pós-eleitoral para responder a nossa questão principal de pesquisa. O método consistiu na verificação dos argumentos contidos em cada um dos discursos expostos na rede social, isto é, as postagens. Esse referencial teórico permitiu a análise de argumentos quase-lógicos, isto é, os racionais, e os argumentos baseados na estrutura do real, os emocionais. Ao todo foram selecionados 16 argumentos para análise.

\section{O SURGIMENTO DO \#YOSOY132}

O candidato Enrique Peña Nieto foi o vitorioso no pleito eleitoral realizado em julho de 2012, assumindo o cargo de presidente em dezembro. O resultado oficial da eleição deu vitória ao candidato Enrique Peña Nieto da coalizão Compromisso por México, formada pelo Partido Revolucionário Institucional (PRI) e pelo Partido Verde Ecologista de México (PVEM) com 38,21\%, Andrés Manuel López Obrador da Coalizão Movimento Progressista, composta pelo Partido da Revolução Democrática (PRD), Partido do Trabalho (PT) e Movimento Cidadão - Convergência (PRD) conquistou 31,59\%, a candidata da situação Josefina Vázquez Mota, do Partido Ação Nacional (PAN) obteve 25,41\%, e Gabriel Quadri de la Torre pelo Partido Nova Aliança (Panal) teve 2,29\%.

No meio do processo eleitoral, Enrique Peña Nieto visitou a Universidade Iberoamericana para apresentação de seu programa de governo. Um grupo de 
ESTRATÉGIAS ARGUMENTATIVAS NO FACEBOOK DO MOVIMENTO \#YOSOY132 PÓS-ELEIÇÃO PRESIDENCIAL MEXICANA DE 2012

estudantes da instituição protestou contra uma repressão legitimada por ele ocorrida na cidade de Atenco, quando o candidato era governador do Estado do México. Peña Nieto disse aos universitários que caso fosse preciso hoje ele faria o mesmo para restabelecer a ordem e a paz. Assim houve protestos de estudantes por toda a instituição. Ao sair disse que aquela não era manifestação de estudantes e sim realizada por inimigos políticos infiltrados.

Assim, um grupo de 131 estudantes gravou um vídeo de 11 minutos intitulado "131 Alumnos de la Ibero responden", postado no site de vídeos YouTube, mostrando que eles eram estudantes da instituição com a apresentação das carteirinhas de estudantes e números de matrículas. O material obteve mais de 1 milhão de visualizações em poucos dias, a ponto de tornar-se um viral nas demais redes sociais com base na internet. Em pouco tempo outros estudantes se somaram ao grupo dizendo que eram o $132 .^{\circ}$ integrante da causa, surgindo o \#YoSoy132. Ao todo, em quinze dias, 52 universidades aderiram às principais causas defendidas: contrários ao retorno do PRI ao poder e à candidatura de Peña Nieto, contra a Televisa fazer campanha para o candidato e a favor da democratização dos meios de comunicação.

Os canais online serviram de espaço estratégico para o misto de ações no offline e online do grupo. Diversos perfis no Facebook e Twitter chamados de "células" foram criados pelos estudantes, simbolizando o movimento em cada um dos 32 estados mexicanos. Outras 52 células internacionais em países de cinco continentes simbolizaram o apoio de mexicanos residentes nesses locais.

En este movimiento, que se mueve con gran seguridad y creatividad, utiliza Facebook para comunicarse y organizarse, confluyen pues una protesta de orden de sectores privilegiados con una protesta democrática contra la imposición, la arbitrariedad, la violencia, la corrupción, con un apoyo sentimental - aunque no programático - a las luchas de las autonomías indígenas². (CASARES, 2012, p. 105, grifos do autor)

1 Vídeo "131 Alunos da Ibero respondem": http://www.youtube.com/watch?v=P7XbocXsFkI 2 Tradução livre: "Neste movimento, que se move com grande segurança e criatividade, utiliza Facebook para comunicar-se e organizar-se, confluem, pois um protesto de ordem de setores privilegiados com um protesto democrático contra a imposição, a arbitrariedade, a violência, a corrupção, com um apoio sentimental - ainda que não programático - as lutas das autonomias indígenas". 
As redes são estruturas comunicativas, formas de organização caracterizadas por voluntarismo, reciprocidade, horizontalidade de comunicação e mudança (KECK; SIKKINK, 1998, p. 3-8). "A rede se converteu em um espaço público fundamental para o fortalecimento das demandas dos atores sociais para ampliar o alcance de suas ações e desenvolver estratégias de luta mais eficazes" (MACHADO, 2007, p. 268). A construção de redes emerge como nova forma de organização das atividades humanas. $O$ equivalente a dizer que vivemos em uma sociedade em rede, termo cunhado por Castells, cuja intenção é descrever e analisar essa nova estrutura social (CAPRA, 2008, p. 18).

$\mathrm{O}$ ambiente virtual tem facilitado os protestos de ativistas, como em emobilizações, isto é, o uso da internet para comunicar, ao facilitar o compartiIhamento de informações de ações de protesto offline. Da mesma forma com os e-movements, como exemplo os movimentos online de votos em que a organização e participação deles ocorrem completamente pela plataforma de veiculação online. (EARL, KIMPORT, 2011, p. 12). "Entre a dupla linha existem numerosas instâncias de ação coletiva com variados graus de componentes offline e online e variados graus de afiliação como movimentos sociais e organizações de movimentos sociais" (EARL, KIMPORT, 2011, p. 8-9, grifos nossos). Os indivíduos vivem em "uma sociedade cuja estrutura social é feita em torno de redes ativadas por tecnologias com base microeletrônica, processada por tecnologias da informação e comunicação" (CASTELLS, 2009, p. 24).

As redes sociais virtuais são importantes para a arena de discussão política. Elas indicam "a necessidade de uma maior exploração dos aspectos políticos de sites de redes sociais como o Facebook" (KUSHIN; KITCHENER, 2009). A criação de grupos no Facebook é uma das formas de comunicação politicamente orientada que leva ativistas a compartilharem vídeos no YouTube ou postarem publicações políticas. Essa forma de participação é chamada de microativismo (MARICHAL, 2010). "A ubiquidade do Facebook, juntamente com a facilidade com que um grupo pode ser formado, faz dessa ferramenta uma forma conveniente de expressão política" (MARICHAL, 2010, p. 3). As redes sociais virtuais têm auxiliado o contato com informação política.

O \#YoSoy132 desenvolveu ações coordenadas nas redes sociais, sites e outros canais de comunicação, realizou demonstrações em estações de metrô. Além disso, organizou marchas pré-eleitorais, dois espetáculos musicais e debate eleitoral 
ESTRATÉGIAS ARGUMENTATIVAS NO FACEBOOK DO MOVIMENTO \#YOSOY132 PÓS-ELEIÇÃO PRESIDENCIAL MEXICANA DE 2012

inédito organizado por estudantes, no qual Enrique Peña Nieto se recusou a participar. Os dois últimos foram transmitidos pela internet. Conforme observado no \#Yosoy132, a articulação das ações originou-se justamente em uma luta simbólica pela visibilidade. Martín-Barbero (2006) corrobora que o desejo dos novos movimentos como dos jovens é de serem reconhecidos e fazerem-se visíveis na sociedade em sua diferença, e não tanto de serem representados.

A identidade é consistente de "relações sociais e suas representações, é vista como uma perspectiva de um ator ou outro (...) e todas as identidades têm um lado político, atual ou potencial” (MCADAM, TARROW, TILLY, 2004, p. 133-134). As tecnologias da informação e comunicação permitem aos movimentos sociais fazer com que parte da população encontre ligação comum e se formem redes (BENNETT; TOFT, 2009).

A internet é considerada como uma "ágora eletrônica (...) oferece a oportunidade de informar o público diretamente, sem a interferência dos meios de comunicação tradicionais e fazer questões e posições mais transparentes e acessíveis" (RUSSMANN, 2010, p. 1). Além disso, disponibiliza ferramentas para a sociedade civil no apoio de suas reivindicações (LAER; AELST, 2009, p. 231) dando suporte para coordenação e esforços de mobilização, que é difícil de observar pela possibilidade de mudar suas formas, estratégias, táticas e objetivos (VAN DE DONK et. al, 2004).

A rede pode encorajar essa heterogeneidade de sujeitos-ativistas, principalmente o interesse de pessoas jovens com a variedade de recursos interativos, que facilita o ativismo e a criação de comunidades por mais que isso não equivalha a uma maior participação política. A internet alterou parte significativa das formas de protesto e estratégias diretas de ação, "promovendo eletronicamente a difusão das ideias de protesto e táticas de forma rápida e eficiente através das fronteiras nacionais" (NORRIS, 2002, p. 208). As pessoas jovens têm sido os "grandes vitoriosos" ou mesmo líderes com a participação pela internet, um espaço político autônomo com base na internet dirigido por jovens (VROMEN, 2008, p. 79).

O ciberativismo é "toda estratégia que persegue a mudança da agenda pública, a inclusão de um novo tema na ordem do dia da grande discussão social, mediante a difusão de uma determinada mensagem e sua propagação através do "boca a boca" multiplicado pelos meios de comunicação e publicação eletrônica pessoal” (UGARTE, 2008, p. 77). O grupo de ativistas utilizou-se, prin- 
cipalmente, das redes sociais com base na internet como espaço estratégico para o desenvolvimento de ações tanto offline quanto online.

As novas formas de ativismo político são facilitadas e encorajadas pela internet (NORRIS, 2000). No ativismo político vislumbram-se oportunidades para a produção direta de material para a difusão de ideias em escala transnacional; possibilidades sem precedentes para a agremiação de novos membros e para a conectividade horizontal. Além disso, possibilita o incremento dos recursos para mobilização de ações coletivas - demonstrações, protestos, boicote - tanto online quanto offline, de modo extremamente rápido e simultâneo através do mundo (MAIA, 2011, p.73, grifos do autor).

\section{ESTRATÉGIAS ARGUMENTATIVAS}

A abordagem teórica utilizada para essa produção é resultado da investigação e estudos no Grupo de Pesquisa Comunicação Eleitoral, da Universidade Federal do Paraná, sobre a Teoria da Argumentação elaborada por Chaïm Perelman e Lucie Olbrechts-Tyteca (1996). O discurso argumentativo é auxiliado pelo uso das técnicas de argumentação. Elas visam influenciar um público específico chamado de auditório pelos autores, que "são usados para transformar as premissas em discursos elaborados com a finalidade de conquistar o auditório e levá-lo à ação" (PANKE, 1999, p. 76). Assim, adotaremos algumas das principais técnicas empregadas na teoria dos autores aplicáveis para o estudo do movimento social \#YoSoy132.

Essa técnica permite a análise de argumentos quase-lógicos, isto é, os racionais, e os argumentos baseados na estrutura do real, os emocionais. No grupo dos argumentos quase-lógicos os autores destacam o uso de diversos argumentos, mas para análises do estudo de caso decidiu-se aplicar seis técnicas que pudessem ser relacionadas com o movimento ou adversários centrais do \#YoSoy132. Os itens de análise escolhidos, conforme descrição abaixo são: contradição, identidade, justiça, transitividade, inclusão da parte no todo e probabilidades.

1) Contradição - revela que as teses combatidas levam a uma incompatibilidade e podem mostrar falhas no discurso oponente e a consequente negação.

2) Identidade - Aliar uma marca a uma ideia resultante de conceitos, classificações ou induções não evidentes, que possibilitam uma justificação argumentativa. 
ESTRATÉGIAS ARGUMENTATIVAS NO FACEBOOK DO MOVIMENTO \#YOSOY132 PÓS-ELEIÇÃO PRESIDENCIAL MEXICANA DE 2012

3) Justiça - Estabelece a coerência de uma conduta. Tenta aplicar as mesmas regras para duas proposições.

4) Transitividade - A noção de identificação de situações, no caso do argumento de justiça acima, é indireta nessa regra de argumentação. Uma situação pode ser afirmada se a é igual a b, b é igual a c, então, a é igual a c.

5) Inclusão da parte no todo - É a inclusão de determinada parte em um todo. Geralmente tratado por um ângulo quantitativo, e resultada em dizer que o todo engloba a parte e é mais importante que ela.

6) Probabilidades - Reflete a indicação de estatísticas e cálculos de probabilidade.

No grupo dos argumentos baseados na estrutura do real, ou seja, na emoção, definiu-se o uso de apenas algumas das técnicas equivalentes à análise eleitoral. Eles buscam estabelecer um elo de solidariedade entre juízos - elementos diversos.

1) Argumento pragmático - permite a apreciação de determinado acontecimento ou ato mediante as conseqüências, presentes ou futuras, sejam elas favoráveis ou não, comumente aceitas, verificáveis ou não. São juízos de valor como numa relação de causa-efeito e não requerem nenhuma justificação. Geralmente em períodos eleitorais apresenta as condições de uma determinada demanda social e o que fazer para solucionar.

2) Argumento dos fins e meios - É usualmente relacionado as técnicas modernas da publicidade e propaganda para explorar a plasticidade da natureza humana.

3) Argumento do desperdício - Refere-se a aceitação por parte do outro de que já iniciado algum progresso ou obra. Elas precisam ser mantidas na mesma direção, independente da não aprovação.

4) Argumento de direção - Busca responder como se dará o desfecho de determinada proposta, estabelecendo pontos de referência e indicando fins parciais para aquela ação. Pode ser entendido como um temor de algo.

5) Argumento de superação - Busca entender que é possível ir mais longe num certo sentido, sem um limite nessa direção estabelecido.

As ligações de coexistência são aquelas que “(...) ressaltam o orador como objeto argumentativo. As ações dele e do grupo que o apóia são tomadas como referencial para valorizar e justificar os argumentos" (Panke, 1999, p. 92). Os 
argumentos dessa ligação utilizados para análise são: da pessoa e seus atos, autoridade, discurso como ato do orador, o grupo e seus membros e a ligação simbólica.

1) Argumento da pessoa e seus atos - Busca reforçar que a imagem do orador é relevante para o público. Na campanha está relacionada com a moral e o direito para julgar o ato e o agente e reforçam as atitudes, valores e realizações.

2) Argumento de autoridade - Está condicionado ao prestígio. É a palavra de honra mais condicionada da visão que outros possuem da outra pessoa ou grupo. São usados atos ou juízos da pessoa/grupo para provar uma tese.

3) Argumento de discurso como ato do orador - O discurso é o ato do orador e esse tipo de argumento relaciona a pessoa ou grupo com suas atitudes. Pode ter casos em que a conversa se dá por mecanismos de forma extrovertida ou persuasão. O uso de discurso de aproximação e jargões é muito próprio desse tipo de técnica.

4) Argumento do grupo e seus membros - É a relação estabelecida entre o grupo e seus membros, "sendo estes a manifestação do grupo, assim como o ato é a expressão da pessoa" (PERELMAN; OLBRECHTS-TYTECA, 1996, p. 366). Ele cria ligação entre integrantes na defesa de teses.

5) Argumento da ligação simbólica - É a relação de participação evocada pela relação do símbolo e o que evoca. São os elementos figurativos que representam uma pessoa ou grupo para despertar alguma reação.

A partir dos conceitos acima, analisamos o \#Yosoy132 durante o período pós-eleitoral, para verificar se as causas defendidas durante as eleições se mantiveram após o pleito, conforme proposição do objetivo principal desse artigo. Assim, selecionamos as dezesseis estratégias argumentativas propostas pela Teoria da Argumentação de Perelman e Olbrechts-Tyteca (1996) citadas para aplicação na rede social Facebook, o principal canal no ambiente online utilizado pelos ativistas do movimento. A base empírica são as 142 postagens realizadas no perfil oficial do Facebook 3 , no período de 03 de julho de 2012 a 03 de dezembro de 2012. O método consistiu na verificação dos argumentos con-

$3<$ https://www.facebook.com/yosoy132>. 
ESTRATÉGIAS ARGUMENTATIVAS NO FACEBOOK DO MOVIMENTO \#YOSOY132 PÓS-ELEIÇÃO PRESIDENCIAL MEXICANA DE 2012

tidos em cada um dos discursos expostos na rede social, isto é, as postagens. Não houve seleção ou exclusão de alguma postagem para a análise. Na análise, observamos a predominância dos argumentos de ligação simbólica (21\%), identidade (19\%) e grupo e seus membros (16\%).

O corpus utilizado consiste de 46 postagens do mês de julho, 20 em agosto, 14 em setembro, 3 em outubro, 38 em novembro e 21 em dezembro. Nesse trabalho, a variação do número de postagens por mês é considerada irrelevante e não afeta a análise das técnicas argumentativas. Diante dos valores obtidos em percentual na análise de seis meses constata-se que a representatividade de cada argumento em relação ao total de postagens é abaixo de $10 \%$ em dez dos 16 argumentos: contradição 6\%, identidade $19 \%$, justiça $5 \%$, transitividade $5 \%$, inclusão da parte no todo $10 \%$, probabilidades 0,07\%, pragmático $13 \%$, dos fins e meios $6 \%$, desperdício $2 \%$, direção $10 \%$, superação $5 \%$, pessoa e seus atos $8 \%$, autoridade $8 \%$, discurso como ato do orador $9 \%$, grupo e seus membros $16 \%$ e ligação simbólica $21 \%$.

Pode-se observar pelos indicadores que mesmo com a predominância de dez técnicas de argumentos baseadas na estrutura do real - emocionais -, os argumentos quase-lógicos - racionais -, foram evidenciados nas postagens no Facebook, com exceção do argumento de probabilidades. No mês de junho, o argumento quase-lógico de identidade (17\%) sobressaiu, assim como entre os meses de setembro a dezembro, com variação de $15 \%$ a $67 \%$. No exemplo abaixo, de 01 de setembro, é possível verificar a tentativa de aliar a marca do ex-presidente Felipe Calderón com conceitos e induções não-evidentes, um argumento de identidade.

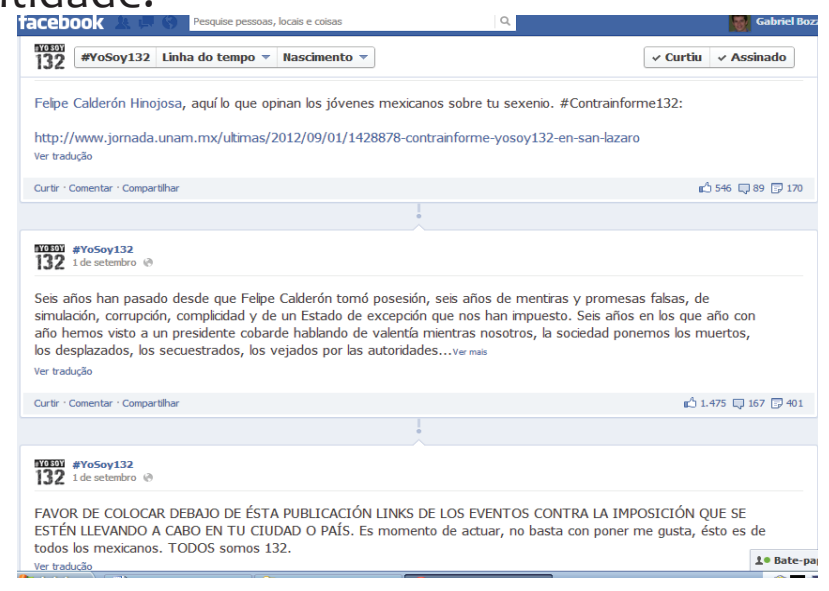

Figura 1 - Exemplo do argumento de identidade na postagem de 01 de setembro de 2012 Fonte: Perfil oficial do Facebook do \#YoSoy132. 
Entretanto, apenas em agosto outra técnica de argumentação pode ser observada que não a de identidade, a contradição (10\%). Nas postagens constatamos no segundo mês pós-eleição a busca por mostrar aos seguidores do perfil a incompatibilidade do discurso do oponente, o presidente eleito Enrique Peña Nieto. Isso significa que o grupo investiu em tentar mostrar as falhas do governo para conseguir adeptos às críticas que realizavam. No gráfico 1 pode ser observada a variação dos argumentos quase-lógicos em cada um dos cinco meses analisados.

Gráfico 1 - Variação argumentos quase-lógicos por mês

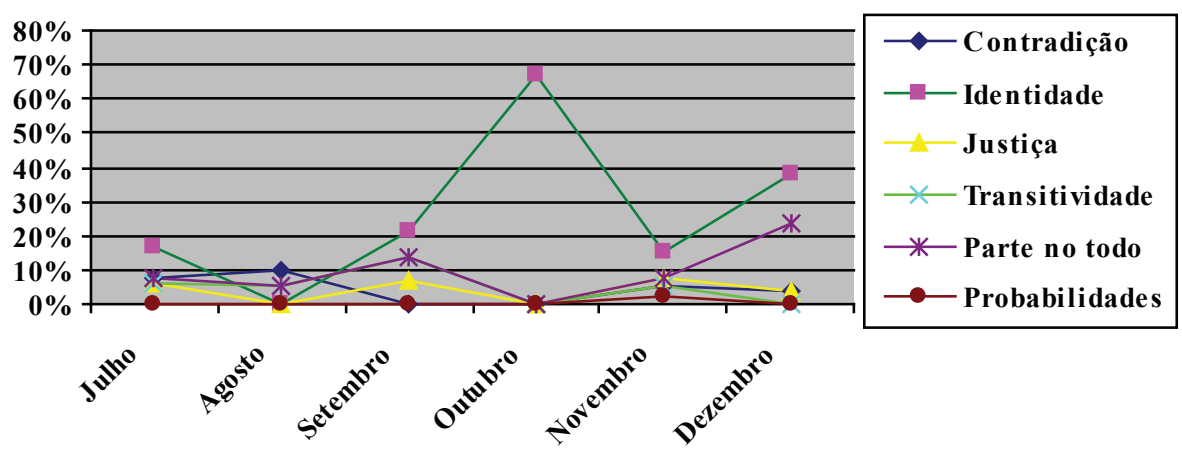

Fonte: (BOZZA, PANKE, 2013)

Entre os argumentos baseados na estrutura do real em cada um dos cinco meses analisados estão aqueles classificados como ligações de sucessão, ou seja, os que revelam um vínculo causal como papel essencial. Pode-se destacar a predominância dos argumentos pragmático e de direção em cada um dos meses analisados, como vemos:

Gráfico 2 - Variação de argumentos de ligação de sucessão por mês

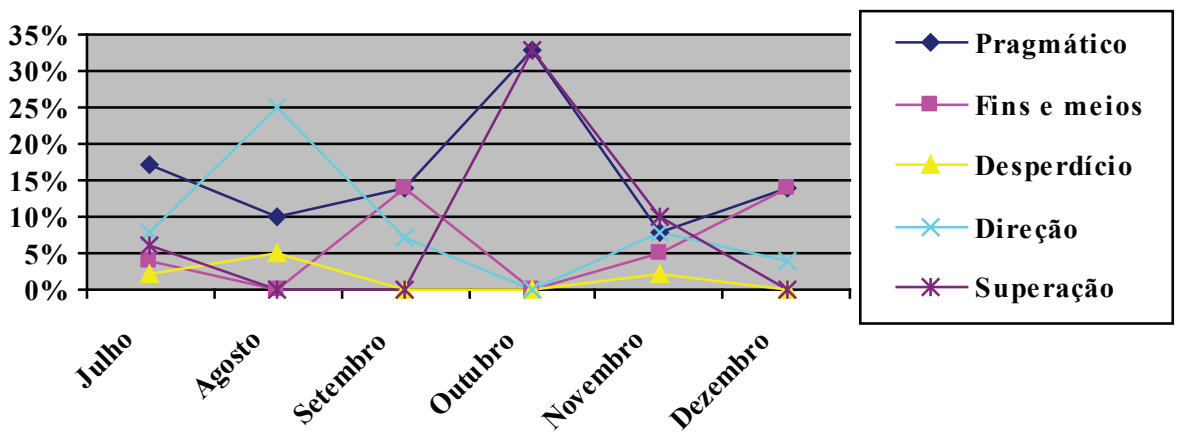

Fonte: (BOZZA, PANKE, 2013) 
No gráfico anterior é possível observar que o argumento de desperdício é irrelevante em todos os meses, assim como o argumento de superação nos três primeiros meses. Entretanto é um dos destaques nos meses de outubro e novembro, que coincide com o movimento vislumbrando de progresso possível de ser ampliado. Assim como não existe um limite para que as ações sejam desenvolvidas, como determinações legais do movimento, na esfera governamental com o investimento no setor de educação.

$\mathrm{O}$ argumento pragmático segue um padrão quase linear. Em julho, ele é destaque sobre os demais em razão de acontecimentos previstos recentemente e com forte juízo de valor numa relação de causa-efeito, muitas vezes não comprováveis, como a compra de votos por dirigentes do partido de Enrique Peña Nieto. No exemplo de 05 de julho é possível perceber isso pela postagem: "Ésta es una parte de la entrevista a Enrique Peña Nieto en BBC World News. ¿Qué estarán "pensando" los que no han recibido sus "centavitos" por la venta de su voto? Difúndanla por favor en contraparte con los videos de el "Sorianagate" y los videos de las personas que se están manifestando y exigiendo el pago de su dinerito".

Nos argumentos baseados na estrutura do real, regidos por ligações de coexistência, constata-se a importância dos argumentos de grupos e seus membros e de ligação simbólica - dois dos três argumentos de destaque entre as 16 técnicas argumentativas. Nos meses de julho, agosto e novembro o argumento de ligação simbólica prevalece ao unir elementos figurativos que representam uma pessoa ou grupo visando reação, como no exemplo abaixo de 06 de julho em que aparece o uso de elementos figurativos na representação de um grupo empregando uma reação:

4 Tradução livre: "Essa é uma parte da entrevista de Enrique Peña Nieto à BBC World News. $O$ que estarão pensando os que não receberam seus "centavitos" pela venda de seu voto? Difundam, por favor, em contrapartida com os vídeos do "Sorianagate" e os vídeos da pessoas que estão manifestando e exigindo o pagamento de seu dinheiro". 


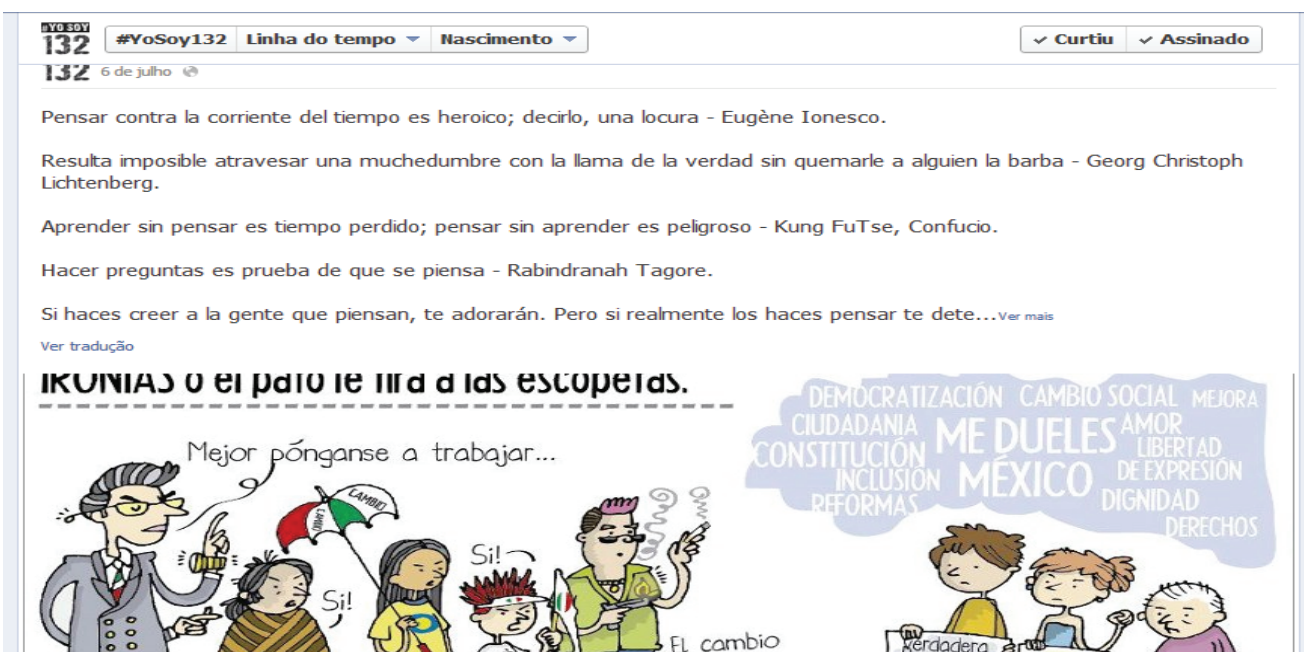

Figura 2 - Exemplo do argumento de ligação simbólica na postagem de 06 de julho de 2012 Fonte: Perfil oficial do Facebook do \#YoSoy132.

O argumento de ligação simbólica perde relevância nas postagens em três únicos meses: em setembro quando o discurso como ato do orador passa a ser destaque em virtude do uso de mecanismos de forma extrovertida ou persuasivas e relacionadas à atitude do próprio movimento social mexicano, e em outubro e dezembro, em que prevalece o argumento do grupo e seus membros, onde são destacadas teses defendidas por ativistas. No último mês analisado, o indicador reflete um manifesto organizado pelo \#YoSoy132 reprimido por força policial. Esse último argumento, mesmo não sendo tão relevante quanto ao de ligação simbólica, é predominante em julho, quando existe a tentativa de provar ilegalidades no pleito, com a compra de votos.

Gráfico 3 - Variação de argumentos de ligação de coexistência por mês

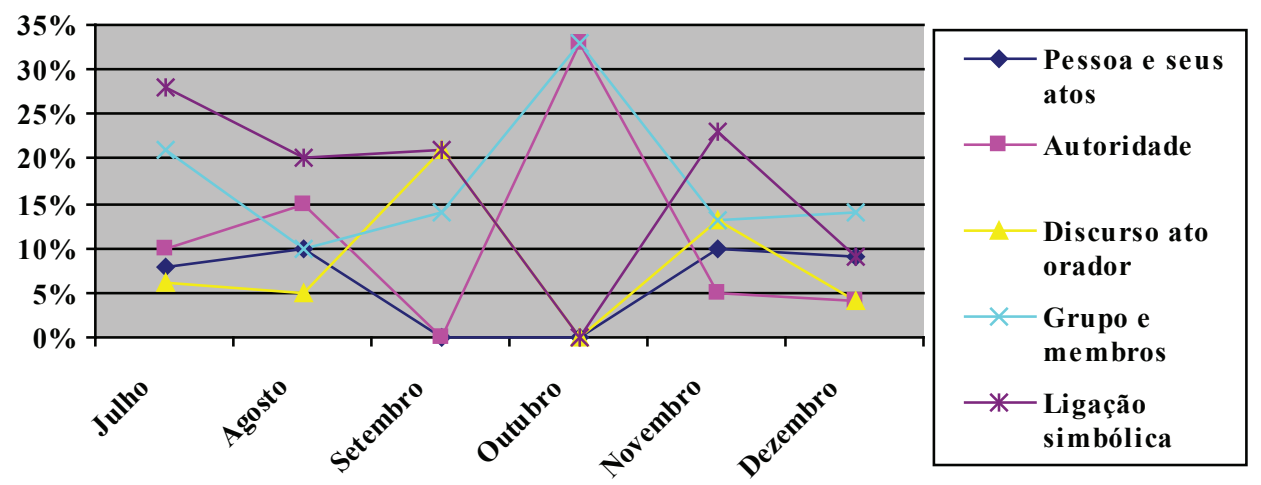

Fonte: (BOZZA, PANKE, 2013) 
ESTRATÉGIAS ARGUMENTATIVAS NO FACEBOOK DO MOVIMENTO \#YOSOY132 PÓS-ELEIÇÃO PRESIDENCIAL MEXICANA DE 2012

Observamos, com base na análise dos três gráficos, que a predominância dos 16 argumentos geralmente nunca é superior a 40\%, com exceção do argumento quase-lógico identidade que em outubro figurou com $67 \%$ entre todos os argumentos analisados. Entre os seis argumentos quase-lógicos verificamos uma regularidade de aparição independente dos meses analisados. Enquanto nas outras dez técnicas pertencentes aos argumentos baseados na estrutura do real a não-linearidade dos indicadores reflete as diferenças de emotividades em cada um dos seis meses.

\section{CONSIDERAÇÕES FINAIS}

As plataformas de serviços de redes sociais virtuais são canais de comunicação em potencial com capacidade de servir de instrumento para conduzir mensagens, massificá-las e direcioná-las para alvos específicos. Podemos considerar ainda o seu lado comercial para fins de promoção pessoal com possibilidade de pagamento de publicidade para maior visibilidade. O canal oficial do Facebooks utilizado desde o início para transmissão de objetivos e metas ajudou os ciberativistas a tornar o movimento \#YoSoy132 visível, para sua legitimação e pré-institucionalização com corpo diretivo constituído, como, por exemplo, com o surgimento de um grupo operativo midiático e jurídico.

De acordo com a análise e tabulação das postagens, observamos a predominância de três dos dezesseis argumentos analisados: ligação simbólica (21\%), identidade (19\%) e grupos e seus membros (16\%). Os indicadores dos 16 argumentos durante os seis meses analisados não foi superior a $40 \%$ em nenhum dos meses analisados, com exceção do argumento de identidade em outubro que figurou com $67 \%$ entre todos os argumentos analisados. Dentre os argumentos destacados acima, o argumento de ligação simbólica é aquele que exprime uma relação de participação evocada pela relação do símbolo e o que evoca. São os elementos figurativos que representam uma pessoa ou grupo e que despertam atenção.

$\mathrm{O}$ argumento de identidade busca aliar uma marca a uma ideia resultante de conceitos, classificações ou induções não evidentes, que possibilitam uma justificação argumentativa. $\mathrm{O}$ argumento de grupos e seus membros é a téc-

$5<$ http://www.facebook.com/yosoy132> 
nica que indica a relação estabelecida entre o grupo e seus membros, criando ligação entre integrantes da defesa de teses. Com a pesquisa, foi possível verificar que, apesar de ter passado o período eleitoral, o \#Yosoy132 manteve comunicação ativa entre seus integrantes e a sociedade mexicana. As técnicas argumentativas utilizadas no Facebook indicam, justamente, a necessidade de reforçar a ligação entre o grupo e seus adeptos, favorecendo com que a ação não se configure apenas como eleitoral.

\section{REFERÊNCIAS}

BENNETT, W. Lance; TOFT, Amoshaun. Identity, technology, and narratives: transnacional activism and social networks. In CHADWICK, Andrew; HOWARD, Philip. N. Routledge Handbook of Internet Politics. London and New York: Taylor \& Francis Group, 2009, p. 246-260.

BOZZA, Gabriel; PANKE, Luciana. Comunicação e tecnologia no movimento estudantil mexicano \#YoSoy132. Revista de Estudos da Comunicação, PUCPR, v. 13, n.32, set-dez 2012. Disponível em: <http:www2.pucpr.br/reol/index.php/comunicacao?dd1=7426\&dd99=view>. Acesso em: 30 nov. 2012.

CAPRA, Fritjof. Vivendo redes. In: DUARTE, Fábio, QUANDT, Carlos, SOUZA, Queila (org.). 0 tempo das redes. São Paulo: Editora Perspectiva, 1 ed., 2008, p.17-29.

CASARES, Guillermo Almeyra. México: El complejo movimiento \#YoSoy132. In: Escenarios XXI, ano, 3, n. 14, p. 102-106, set-out. 2012. Disponível em: <http://www.escenarios21. com/2012/0121.html\#.UPgFP6xtmQw>. Acesso em: 08 dez. 2012.

CASTELLS, Manuel. Communication power. New York: Oxford University Press, 2009, 571 p. EARL, Jennifer; KIMPORT, Katrina. Digitally enabled social change: activism in the internet age. Cambridge: Massachusetts Institute of Technology, 2011, 258p.

KECK, Margaret E.; SIKKINK, Kathryn. Activists beyond borders: advocacy networks in international politics. Ithaca, New York, Cornell University Press, 1998, 228 p.

KUSHIN, Matthew J.; KITCHENER, Kelin. Getting political on social network sites: Exploring online political discourse on Facebook. In First Monday, vol. 14, $n^{\circ} 11$, nov. 2009. Disponível em: <http://firstmonday.org/article/view/2645/2350>. Acesso em: 16 fev. 2013.

LAER, Jeroen Van; AELST, Peter Van. Cyber-protest and civil society: the Internet and action repertoires in social movements. In JEWKES, Yvonne; YAR, Majid. Handbook of Internet Crime. London: Willan Publishing, 2009, p. 230-254. Disponível em: <http://www.m2p.be/index. php?page=publications\&id=117>. Acesso em: 08 abr. 2013.

MACHADO, Jorge Almeida S. Ativismo em rede e conexões identitárias: novas perspectivas para os movimentos sociais. In Sociologias. Porto Alegre: ano 9, $n^{\circ} 18$, jul-dez. 2007, p. 248285. 
ESTRATÉGIAS ARGUMENTATIVAS NO FACEBOOK DO MOVIMENTO \#YOSOY132 PÓS-ELEIÇÃO PRESIDENCIAL MEXICANA DE 2012

MAIA, Rousiley Celi Moreira (org.). Internet e esfera civil: Limites e alcances da participação política. In MAIA, Rousiley Celi Moreira; GOMES, Wilson; MARQUES, Francisco Paulo Jamil Almeida. Internet e participação política no Brasil. Porto Alegre: Sulina, 2011.

MARICHAL, José. Political Facebook Groups: Micro-Activism and the Digital Front Stage. In Internet, Politics, Policy 2010: An Impact Assessment. Oxford Internet Institute, 2010. Disponível em: <http://microsites.oii.ox.ac.uk/ipp2010/system/files/IPP2010_Marichal_Paper.pdf>. Acesso em: 17 fev. 2013.

MARTÍN-BARBERO, J. Tecnicidades, identidades, alteridades: mudanças e opacidades da comunicação no novo século. In: MORAES, D. Sociedade midiatizada. Rio de Janeiro: Mauad, 2006. p.71-86.

MCADAM, Doug, TARROW, Sidney, TILLY, Charles. Dynamics of Contention. Cambridge: University Press, 2004

MELUCCI, Alberto. Challenging codes: collective action in the information age. Cambridge: University Press, 1996, 441p.

NORRIS, Pippa. A Vituous Circle: Political Communications in Postindustrial Societes. New York: Cambridge University Press, 2000.

. Democratic Phoenix: reinventing political activism. Cambridge University Press, 2002.

PANKE, Luciana. O papel da linguagem na criação de uma imagem. Um estudo de caso: José Eduardo Vieira, o banqueiro senador dos trabalhadores. Curitiba, 1999. Dissertação (Mestrado em Letras). Curso de Pós-Graduação em Linguística da Língua Portuguesa, Universidade Federal do Paraná.

PERELMAN, Chaïm; OLBRECHTS-TYTECA, Lucie. Tratado da Argumentação - A nova retórica. São Paulo: Martins Fontes, 1996, p. 580.

RUSSMANN, Uta. Parties and Candidates on the Web - A Cross-national Comparison of Party and Candidate Website Commmunication in the 2008 Austrian and 2009 German National Elections. In Workshop: Elections, Compaigning and Citizen Online. Oxford Internet Institute, 2010. Disponível em: <http://drupals.humanities.manchester.ac.uk/ipol/sites/ default/files/ecco/Russmann.pdf>. Acesso em: 16 fev. 2013.

TARROW, Sidney. O poder em movimento: movimentos sociais e confronto político. Petrópolis: Vozes, 2009.

UGARTE, David de. O poder das redes: manual ilustrado para pessoas, organizações e empresas, chamadas a praticar o ciberativismo. Porto Alegre: EDIPUCRS, 2008, 116 p.

VAN DE DONK, W., LOADER, B. D., NIXON, P. G; RUCHT, D. Introduction: Social Movements and ICTs. In VAN DE DONK, W., LOADER, B. D., NIXON, P. G; RUCHT, D. (eds.), Cyberprotest. New media, citizens and social movements. London: Routledge, 2004, p. 1-26

VROMEN, A. Building Virtual Spaces: Young People, Participation and the Internet. In: Australian Journal of Political Science, vol. 43, n. ${ }^{\circ}$ 1, mar, 2008, p.79-97. 
WOLTON, Dominique. Internet e depois? Uma teoria crítica das novas mídias. Porto Alegre: Sulina, 3. ed., 2012, 229 p.

RECEBIDO EM: 24/05/2013

ACEITO PARA PUBLICAÇÃO: 20/11/2013

\section{Gabriel Bozza}

Mestrando em Comunicação da Universidade Federal do Paraná (UFPR), sob orientação da Profo ${ }^{\circ}$ r. $^{a}$ Luciana Panke. Pesquisador dos grupos de pesquisa "Comunicação Eleitoral" e "Comunicação e Mobilização Política" da UFPR. Associado da Sociedade Brasileira de Profissionais e Pesquisadores de Marketing Político (Politicom). Bacharel em Comunicação Social com habilitação em Jornalismo pela PUCPR. Bolsista Reuni.

\section{Luciana Panke}

Em estágio pós-doutoral na Universidade Autônoma Metropolitana - México (UAM), Distrito Federal, com bolsa Capes. Doutora em Ciências da Comunicação (USP). Professora da Universidade Federal do Paraná (UFPR) no curso de graduação em Comunicação Social (Publicidade e Propaganda) e do Programa de Pós-Graduação em Comunicação. Vice-presidente da Sociedade Brasileira de Profissionais e Pesquisadores de Marketing Político (Politicom) e líder do grupo de pesquisa "Comunicação Eleitoral". 
